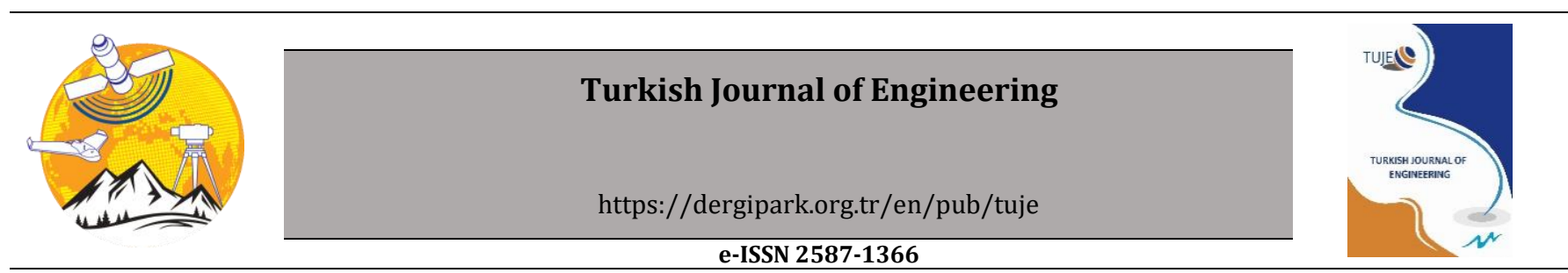

\title{
Research on A1 irregularity status in different spectral acceleration coefficients on reinforced concrete structures
}

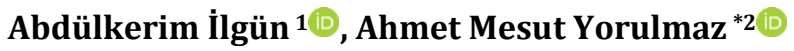 \\ ${ }^{1}$ Kto Karatay University, Faculty of Engineering, Department of Civil Engineering, Konya, Turkey \\ ${ }^{2}$ Konya Technical University, Faculty of Engineering, Department of Civil Engineering, Konya, Turkey
}

\section{Keywords}

Torsional irregularity

Reinforced concrete structure

Structural behavior

Geometric form

\begin{abstract}
Most of the building damages in our country are caused by earthquakes. As known, the properties of the building are determinant in the magnitude of the earthquake forces that cause these damages. Thus, selection of the structural system is crucial in the design process. In case of any irregularity in the building, load transfer will not be provided safely. In the Turkish Earthquake Code, related irregularities are analysed under two groups. Group A indicates the irregularities in the plan, and Group B represents vertical irregularities. Irregularities in the plan include A1 Torsional Irregularities; A2 Floor Discontinuities; and A3 Bulges in the Plan. In this study, A1 irregularity status in the reinforced concrete structure was analysed for different spectral acceleration coefficients. The purpose of the study is to understand the change of torsional irregularity coefficient in different spectral acceleration coefficients. As a result, in a typical building with the same geometric and stiffness properties, the torsional irregularity coefficient is not changed for different earthquake zones. Also, the importance of the location of the shear wall elements in the plan was once again emphasized.
\end{abstract}

\section{INTRODUCTION}

In general, the construction is designed considering the necessity of being economical, aesthetic, and safe. Therefore, it is more important than other issues to ensure the safety of the structure, that is, to provide reliability in the event of collapse, except for displacement and section cracks under the characteristic loads. Such displacements are manifested by inertial forces in the event of an earthquake. All this led to the development of contemporary earthquake regulations. In general, all International earthquake regulations are aimed at ensuring that the structure can easily be repaired in relatively less severe earthquakes and that the structure does not collapse in severe earthquakes and that there is no loss of life.

One of the most striking issues in regulations is Torsional Irregularity. The relevant regulations have brought some limitations to irregularities. These are issues such as increasing eccentricity or performing dynamic analysis if the specified limits are exceeded.

(Yön and Sayın 2009) in order to examine the changes in the total torsional moment of different floor classes in a structure with torsional irregularity, a multi-storey reinforced concrete building with shear wall-frame according to the torsional irregularity specified in the Turkish Earthquake Regulation (TDY-2007) was designed and the results of the analysis were evaluated.

(Erdem 2016) in case construction's structural systems are not selected in line with the principles of earthquake-resistant structural systems selection, the impacts of torsional irregularities caused by not having overlapped the mass and stiffness of the structures are analyzed by changing the column sizes and forming structural systems with different eccentricity and stiffness.

(Özmen 2004), analyzed the conditions required for the torsional irregularity coefficient to exceed the upper limit of 2.00 using a parametric research method, 8 typical building groups with shear walls in different positions were selected and their behaviors under earthquake loads were evaluated.

(Demir and Dönmez 2008), factors affecting torsional irregularities, according to the conditions of the "Regulation on Buildings to be Made in Earthquake Zones", of six types of structures with different 
geometrical plans and shear wall layouts and four local floor classes were examined.

(Özmen 2012), in order to examine the validity of the torsional irregularity coefficients in regulations, six groups of typical structures with different shear wall positions were selected. The number of axles for these structures was changed between 5,6 and 7 , and the number of floors was changed between 1, 2, 4, 6, 8 and 10 , and the variation of the torsional irregularity coefficients was examined.

(Doğan and Er 2010) torsional irregularity changes, due to the live load distribution is not evenly spread in the floor plane in residential buildings, were analysed.

(Demir et al. 2011), analysed the change in torsional behaviour of different floor classes of an existing reinforced concrete hospital building with the Equivalent Earthquake Load, Mode Combination and Calculation in Time history methods mentioned in Turkish Earthquake Regulation-2007 for four different local floor classes and studied the effect of scaled earthquake records on various behaviours of the building.

(Özmen 2001), in order to ensure that there is no geometrical irregularity effect, rectangle plan geometry was selected and analysed in all typical structures with regular and irregular stiffness distribution where earthquake calculation and dimension results are dealt with.

Döndüren et al. 2007, torsional irregularity conditions in symmetrical and non-symmetrical structures in terms of plan geometry and stiffness distribution and their behaviours under earthquake effects were analysed considering multi-storey structures in seven different types with 15-storey triangle, ellipse, square, rectangle, circular, $\mathrm{L}$ and $\mathrm{T}$ shaped geometry.

(Soyluk and Yavuz 2009) (Özmen 2000) analysed the impact of plan geometry on torsional irregularity. (Özmen 2000) analysed the impact of plan geometry on torsional irregularity. (Uçar and Merter 2009) analyzed the impact of shear wall placement on the earthquake behaviour of the reinforced shear wall-framed buildings by considering torsional irregularity coefficients.

(Yorulmaz 2018), in his master thesis study, analyzed the change of the torsional irregularity coefficient for different earthquake zones in reinforced concrete structures according to TDY-2007 and as a conclusion, it was shown that the differentiation of the earthquake zones did not change the torsional irregularity coefficient.

\section{A1 TORSIONAL IRREGULARITY}

Torsional Irregularity, for any of the two earthquake directions perpendicular to each other in TBDY-2018, is expressed as the ratio of the largest relative floor displacement in any floor to the average relative displacement in that direction.

With a simple approach, designing buildings solely according to earthquake forces does not fully serve the purpose. The irregularities in the plan of the structure create additional torsional moments. This is shown in Figure 1 and Figure 2 below.
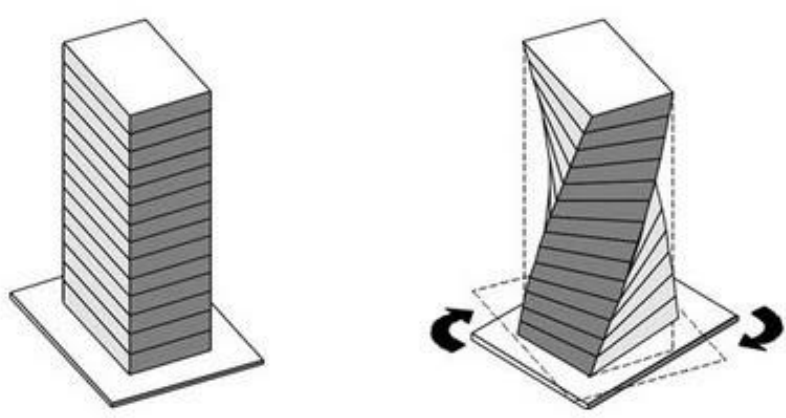

Figure 1. Representation of the torsional moment in the structure

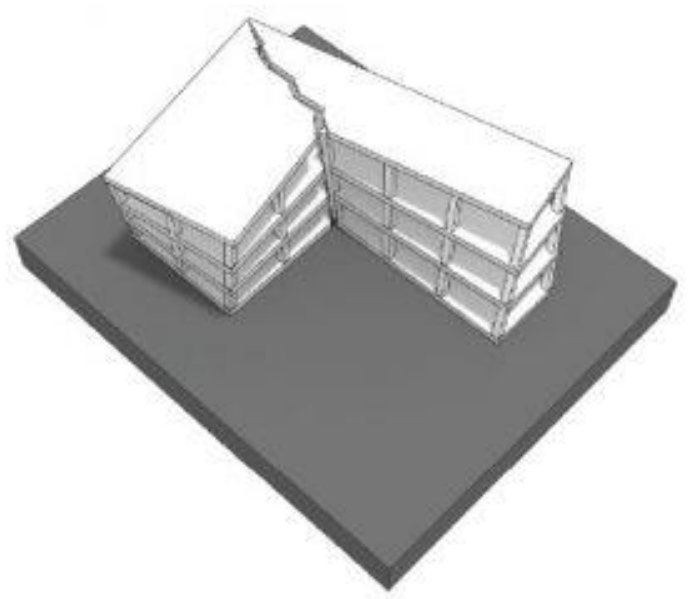

Figure 2. Representation of the torsional moment in the structure

\subsection{Torsional Irregularity Calculation}

Inertial forces occurring during the earthquake affecting the structure's centre of gravity. The structure tries to spin around the stiffness centre. Since the centre of gravity and stiffness do not coincide, a torsional moment occurs in the structure (Figure 3). Therefore, the stiffness centres of shear walls and columns, which are among the elements with relatively high stiffness, should be positioned as close to the centre of gravity of structure as possible. Especially, shear wall elements should be positioned outside the structure.

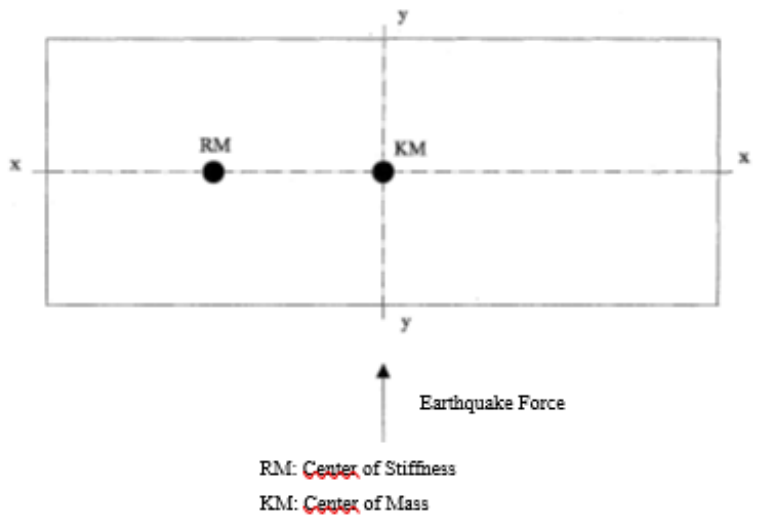

Figure 3. Representation of stiffness centre and mass centre 
When international earthquake regulations are analysed, it is seen that one of the most frequently considered irregularity is Torsional Irregularity. Torsional irregularity depends on the torsional irregularity coefficient calculated as the ratio of maximum relative displacement to the average relative displacement of the floor under consideration.

For any of the two earthquake directions perpendicular to each other in TBDY-2018, the Torsional Irregularity Coefficient $\eta_{\text {bi }}$ which represent the ratio of the largest relative floor displacement in one floor to the average relative displacement in that same direction is greater than 1.2 torsional irregularity should be taken into consideration.

$$
\begin{gathered}
\eta \mathrm{bi}=\left(\Delta_{\mathrm{i}}\right)_{\max } /\left(\Delta_{\mathrm{i}}\right)_{\text {ort }>1.2} \\
\left(\Delta_{\mathrm{i}}\right)_{\max }\left(\mathrm{d}_{\mathrm{i}}\right)_{\max }\left(\mathrm{d}_{\mathrm{i}}-1\right)_{\max } \\
\left(\Delta_{\mathrm{i}}\right)_{\min }=\left(\mathrm{d}_{\mathrm{i}}\right)_{\min }-\left(\mathrm{d}_{\mathrm{i}}-1\right)_{\min } \\
\left.\left(\Delta_{\mathrm{i}}\right)_{\text {ort }}=\left(\left(\Delta_{\mathrm{i}}\right)_{\max }+\left(\Delta_{\mathrm{i}}\right)_{\min }\right)\right) / 2
\end{gathered}
$$

$\mathrm{d}_{\mathrm{i}}=$ Displacement calculated according to earthquake loads on floor "i" of the building.

$\left(\Delta_{\mathrm{i}}\right)_{\max }=$ Maximum relative floor displacement on floor $\mathrm{i}$ of the building.

The relative floor displacement that causes the torsional irregularity below (Figure 4) is shown as shown in TBDY-2018.

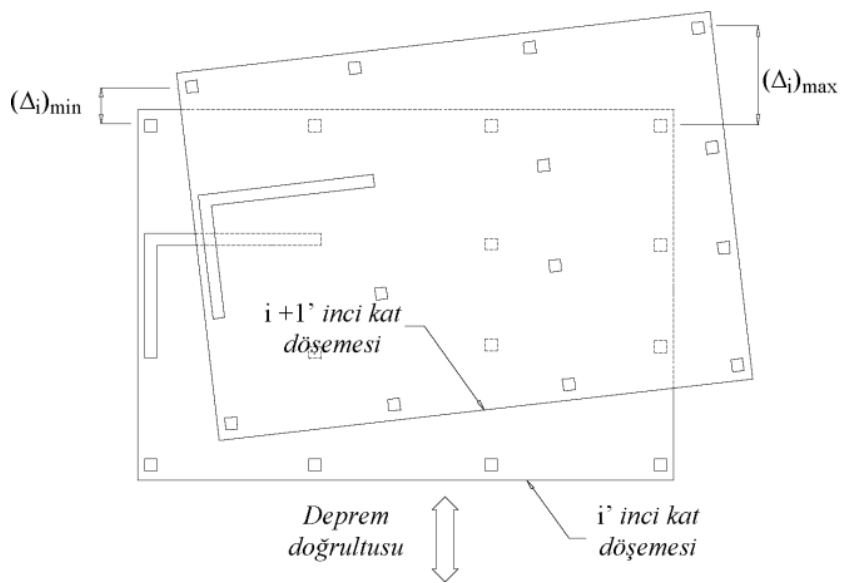

Figure 4. Relative floor displacement

If the torsional coefficient is greater than 1.2 on any floor as a result of the analysis, as stated in Article 4.7.4 of TBDY-2018, on condition that $1.2<\eta_{\mathrm{bi}} \leq 2.0$ is greater than $2.0, \pm 5 \%$ additional eccentricity applied on this floor will be magnified by multiplying with the coefficient $D_{i}$ for both earthquake directions (eq. 5).

$$
\operatorname{Di}=\left(\frac{\eta b i}{1,2}\right)
$$

In cases where the torsional coefficient exceeds the limit of 2.00 one of the dynamic analysis methods stated in the related regulation should be applied.

\subsection{The Effect of Plan Geometry and Stiffness Distribution on Torsion}

Ideally, the most suitable structures are the square type structures that are symmetrical in plan and cross- section. In such structures, the structure's centre of gravity and centre of stiffness is almost at the same place. However, this is often not possible due to architectural reasons. Torsional moment occurring in such structures with different geometries causes additional shear forces in the structures. In this regard, the stiffness distribution is more important than geometry. In cases where geometric figures cannot be avoided, stiffness distribution should be taken into account in order to prevent structure torsion. In addition, torsion can also be observed in structures that are symmetrical in terms of plan geometry and stiffness distribution, or where the centre of gravity and stiffness centre coincide. The reason for torsion here is that the stiffness of the elements in outer axles is relatively lower. The fact that the elevator shear walls are mostly planned in the core can be the best example of this.

The results of plan geometry and stiffness distribution can be listed as follows (Özmen 2001),

-In structures with irregularities in terms of stiffness distribution, torsional irregularity can be very high.

-Even in the most unfavorable structures in terms of torsion, $\eta_{b i}$ the torsional irregularity coefficients remain below 2.00, which is the limit value for the equivalent seismic load application.

-The torsional irregularity can mostly be improved with the arrangements to be made on the weak axes of such structures in the carrier elements.

-The most effective method to improve torsional irregularities is to place shear walls on weak axes, albeit in limited numbers and sizes.

-Increasing the column or beam dimensions in weak axes is also beneficial decreasing torsional irregularity.

-Even in the structures with high torsional irregularities, no significant negativity is experienced in terms of sizing. It can be argued that amendments should be made in the measures for the foreseen torsional irregularities in the regulations.

-It can be said that stiffness distribution is a more important factor in terms of torsional irregularity than geometry.

\section{ANALYSIS ON TORSIONAL IRREGULARITY FOR DIFFERENT SPECTRAL ACCELERATION COEFFICIENTS}

\subsection{Examined Structure Type}

In order to interpret the torsional irregularity coefficients in the structures for different spectral acceleration coefficients, the structure was examined separately by selecting 3 different locations on Turkey Earthquake Hazard Maps Interactive Web Application (Table 2), on condition that geometric and stiffness values remain the same for the specific structure (Figure 5 and Figure 6). All analyses of the structure were made using the Etabs 18.1.1 program, and the information about the structure and the selected location are given in Table 1. 
Table 1. Information about the structure

\begin{tabular}{lc}
\hline Information & Value \\
\hline Total Structure Height & $30 \mathrm{~m}$ \\
Number of Floors & 10 \\
Building Importance & 1 \\
Coefficient(I) & \\
Behaviour Coefficient (R) & 7 \\
Overstrength Coefficient (D) & 2.5 \\
Local Floor Class & $\mathrm{ZB}$ \\
Column Size & $50 \mathrm{~cm} * 50 \mathrm{~cm}$ \\
Beam Size & $30 \mathrm{~cm} * 60 \mathrm{~cm}$ \\
Shear Wall Width & $30 \mathrm{~cm}$ \\
Floor Thickness & $20 \mathrm{~cm}$ \\
Coating Load & $2 \mathrm{kN} / \mathrm{m}^{2}$ \\
Live Load & $2 \mathrm{kN} / \mathrm{m}^{2}$ \\
Concrete Class & $\mathrm{C} 30$ \\
Reinforcement Class & $\mathrm{S} 420$ \\
\hline
\end{tabular}

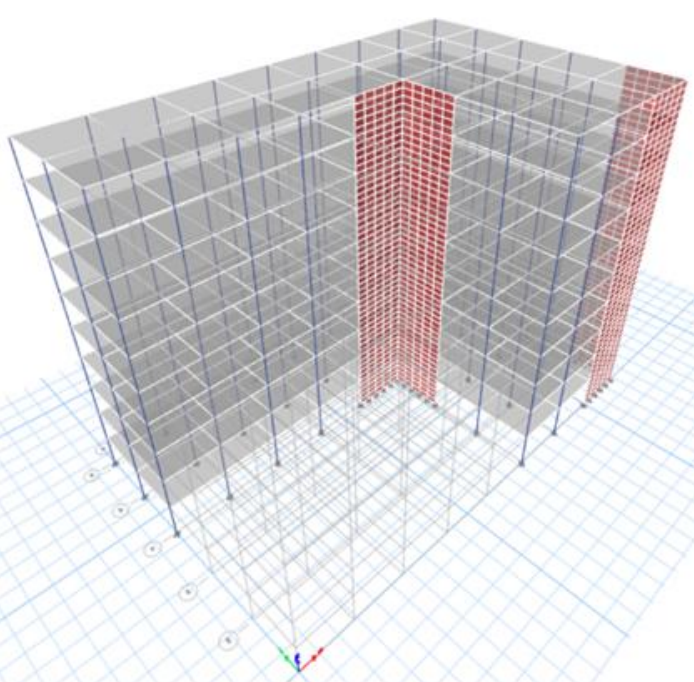

Figure 5. 3D view of the studied structure

Table 2. Location acceleration data

\begin{tabular}{lcccccccc}
\hline & Latitude & Longitude & $\mathrm{S}_{\mathrm{S}}$ & $\mathrm{S}_{1}$ & $\mathrm{~S}_{\mathrm{DS}}$ & $\mathrm{S}_{\mathrm{D} 1}$ & PGA & PGV \\
\hline Location-1 & $37.169372^{\circ}$ & $33.226919^{\circ}$ & 0.235 & 0.059 & 0.211 & 0.047 & 0.104 & 5.219 \\
Location-2 & $37.269234^{\circ}$ & $29.615972^{\circ}$ & 0.894 & 0.218 & 0.805 & 0.174 & 0.386 & 20.442 \\
Location-3 & $40.618555^{\circ}$ & $29.991237^{\circ}$ & 1.506 & 0.414 & 1.355 & 0.331 & 0.613 & 38.118 \\
\hline
\end{tabular}

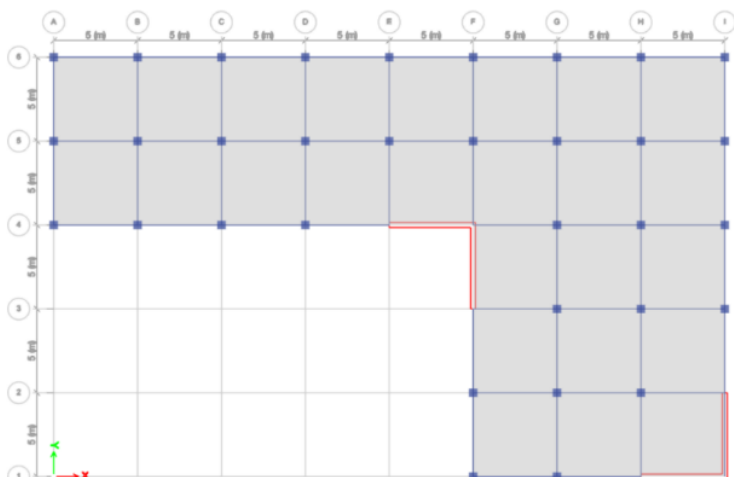

Figure 6. Plan of studied structure

\subsection{Analysis Results of the Studied Structure}

As a result of the analysis of the structure, the graphs of the torsional irregularity coefficient in figures 7 and 8 were obtained. As seen in related figures, torsional irregularities exist in both directions of the structures.

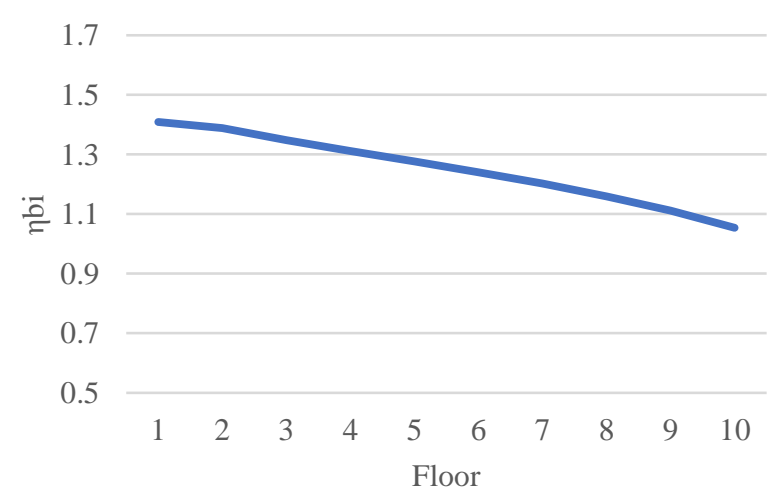

$\longrightarrow$ Location-1 Location-2 Location-3

Figure 7. Comparison of torsional irregularity coefficient in $\mathrm{X}$ direction for different spectral acceleration coefficients

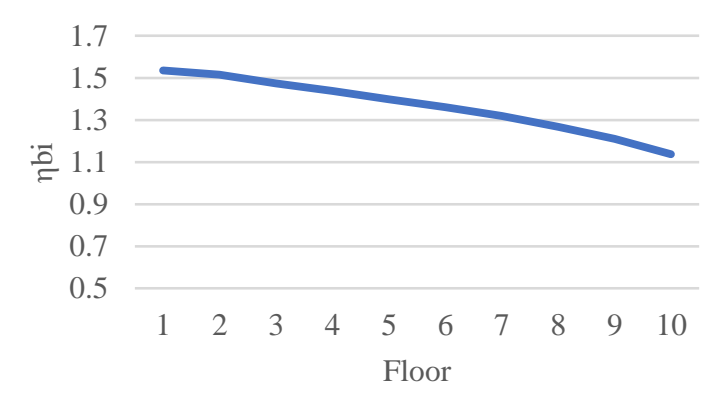

$\longrightarrow$ Location-1 Location-2 Location-3

Figure 8. Comparison of torsional irregularity coefficient in $\mathrm{Y}$ direction for different spectral acceleration coefficients

\subsection{Solution Proposal and Results for Torsional Irregularity in the Analysed Structure}

In addition to the results of the analysed structure, in order to draw attention to the importance of the location of the shear wall elements, the structure was analysed again only by changing the location without changing the shear wall widths and number (Figure 9 and Figure 10), and the torsional irregularity coefficient was examined.

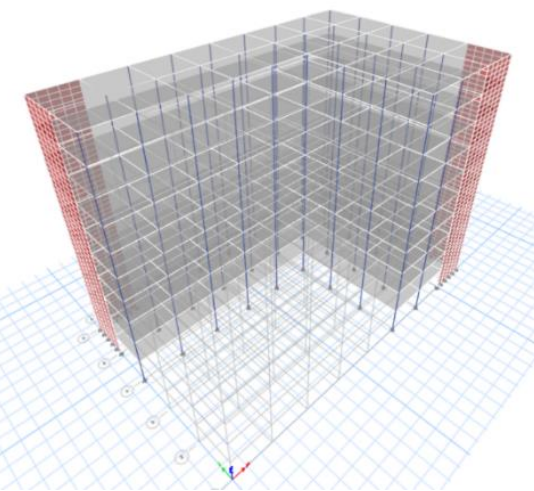

Figure 9. 3D View of the structure with stiffness adjustment 


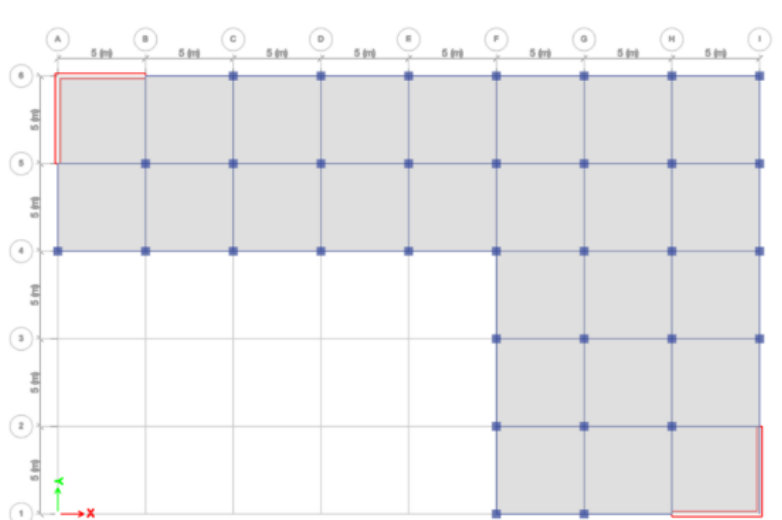

Figure 10. Plan of the structure with stiffness arrangement

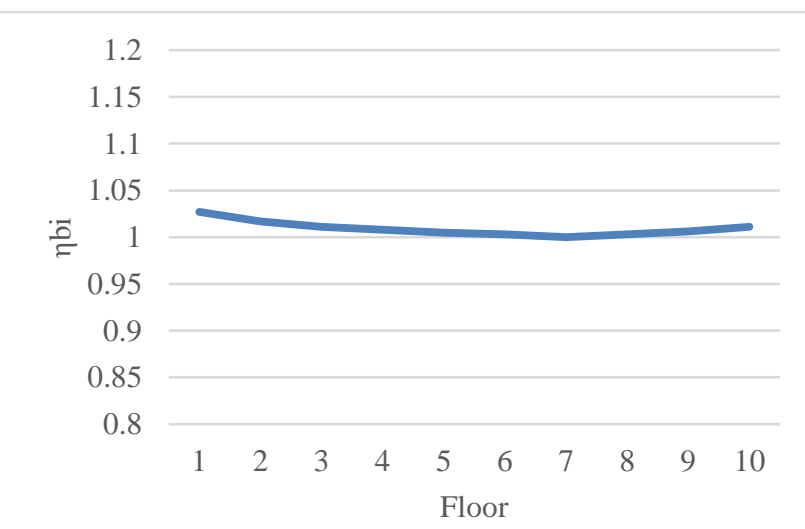

Location-1 Location-2 Location-3

Figure 11. Comparison of torsional irregularity coefficient in $\mathrm{X}$ direction for different spectral acceleration coefficients of the adjusted structure

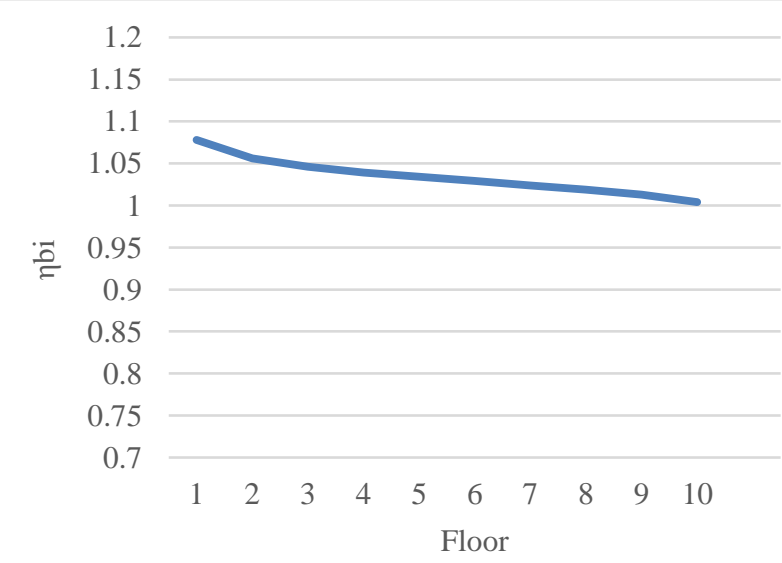

$\longrightarrow$ Location-1 Location-2 Location-3

Figure 12. Comparison of torsional irregularity 4 coefficient in $\mathrm{Y}$ direction for different spectral acceleration coefficients of the adjusted structure

\section{RESULTS AND RECOMMENDATIONS}

The most important result of the study is that the analysis of the same structure for different spectral acceleration coefficients, without changing the structure plan geometry and stiffness distribution, does not change the torsional irregularity coefficient.

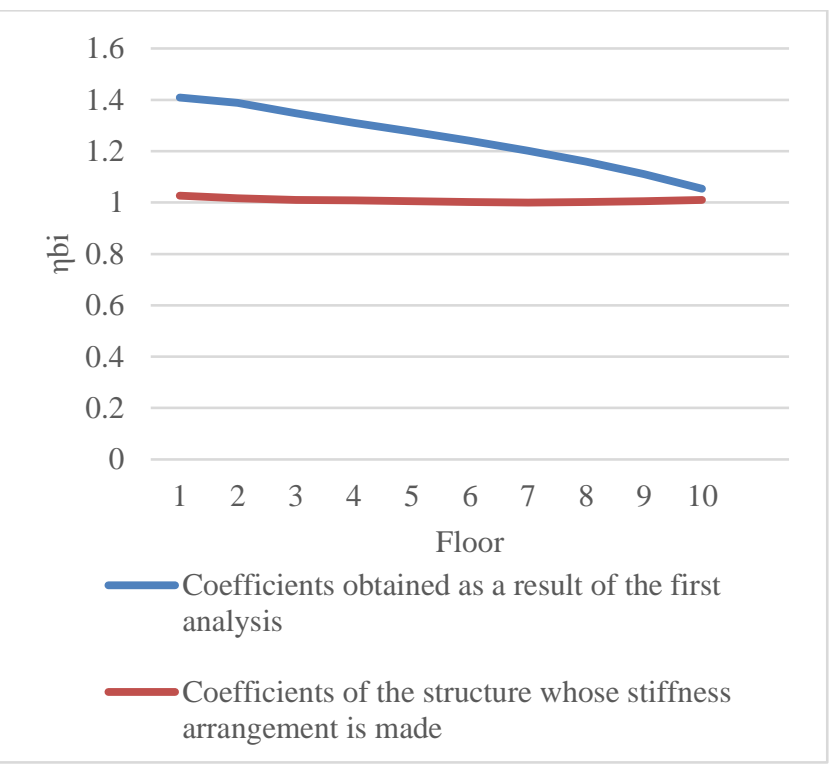

Figure 13. Comparison of torsion irregularity coefficients in the $\mathrm{X}$ Direction

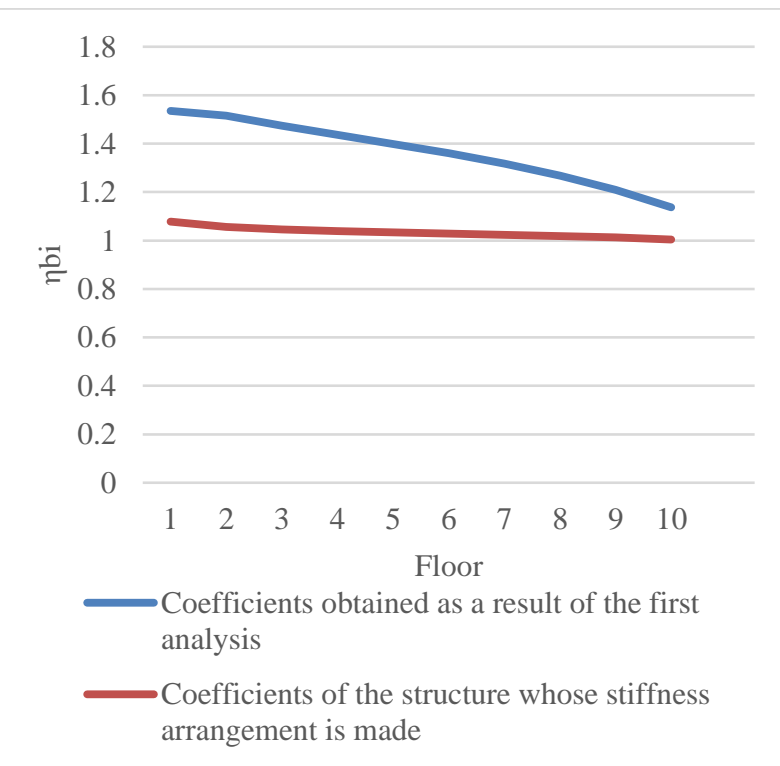

Figure 14. Comparison of torsion irregularity coefficients in the $\mathrm{Y}$ direction

Although different displacements and different torsional moments are obtained in the analysis results, the change in ground class and differentiation of static or dynamic loading states will not change the torsional irregularity coefficient. The torsional irregularity coefficient is ultimately a ratio, which is associated with the structure plan geometry and stiffness distribution (Yorulmaz 2018).

In Section 3.3, in order to draw attention to the position of the shear wall elements in terms of Civil Engineering discipline, it was seen that the torsional irregularity coefficient was reduced to reasonable levels by changing the positions only, without changing the number and size of the existing shear wall elements (Figure 13 and Figure 14).

When Figure 11 and Figure 12 are analyzed, the torsional irregularity coefficient of the structure, where the stiffness adjustment is made, is lower than 1.2 , that's 
why lower stresses will occur in the elements and sections compared to other solutions.

Studies in the literature and the analyses done by us have once again shown that being able to model buildings in regular form is more important than the material and site environment in designing structures. Even though all the construction is done in accordance with the technique, placing the elements with insufficient and irregular stiffness in the unsuitable places will extremely force the structure at the time of the earthquake. It should not be forgotten that irregularities are extremely important for structure safety.

\section{REFERENCES}

Demir A \& Dönmez D (2008). The factors affecting torsional irregularity in multi-storey structures. Celal Bayar University Journal of Science, 4(1), 31-36.

Demir A, Bağcı M \& Demir D D (2011). Torsional behavior of an existing hospital building in different site classes. Celal Bayar University Journal of Science, 7(1), 17-27.

Doğan O \& Er Ş B (2010). Live load distribution investigation of the impact on torsional irregularity. International Journal of Engineering Research and Development, 2(2), 57-60.

Döndüren M S, Karaduman A, Çöğürcü M T \& Altın M (2007). Torsional irregularity in the structures. Journal of Selcuk-Technic, 6(1), 42-52.

Erdem H (2016). Effects of torsional irregularity on reinforced concrete behaviour. Çukurova University
Journal of the Faculty of Engineering and Architecture, 31(1), 459-468.

Özmen G (2000). The effect of plan geometry on torsional irregularity. Turkey Engineering News, 410(6), 3741.

Özmen G (2001). Effect of stiffness distribution on torsional irregularity. Turkey Engineering News, 411(1), 37-40.

Özmen G (2004). Excessive torsional irregularity in multi-story structures. Technical Journal, 15(1), 3131-3144.

Özmen G (2012). Torsional irregularity conditions in earthquake regulations. Turkey engineering news, 57 (2), 52-64.

Soyluk K \& Yavuz İ Y (2009). Effect of Basement Retaining Walls to torsional irregularity in frame type. İmo technical journal, 20(97), 4654-4673.

Uçar T \& Merter 0 (2009). Effect of configuration of shear walls at floor plan to earthquake behavior of shear wall-frame reinforced concrete buildings. Deu journal of Engineering Science, 11(2), 11-18.

Yorulmaz A M (2018). Investigation of A1 irregularity in reinforced concrete for different earthquake zone, MS Thesis, University of Kto Karatay, Konya, Turkey.

Yön B \& Sayın E (2009). Investigation of effect of local site classes to columns behavior on structures with torsional irregularity. e-journal of New World Science Academy, 4(2), 126-135.

(C) Author(s) 2021.

This work is distributed under https://creativecommons.org/licenses/by-sa/4.0/ 